\title{
O Western americano na poética de Glauber Rocha e "Deus e o Diabo na Terra do Sol" Fabiana da Camara Gonçalves Pereira"
}

\section{RESUMO}

Neste trabalho trataremos das relaçōes entre Deus e o Diabo na Terra do Sol, filme dirigido por Glauber Rocha em 1963, e sua relaçāo com a tradição do western desenvolvida até esse momento. Para consegui-lo, abordaremos um pouco da história do gênero e traçaremos sua evolução dos primórdios do cinema mudo até a década de 1960, nas produções hollywoodianas. Também lançaremos um breve olhar sobre o ciclo de filmes sobre o cangaço, ou nordestern, ocorrido no Brasil entre 1950 e 1960 . A formaçāo estética de Glauber, sua práxis criativa e o inegável engajamento no estabelecimento e renovação do Cinema Novo também são fatores es. senciais. O entrecruzar destas trajetórias nos ajudará a compreender os pontos de interesse do cineasta - rupturas e continuidades - além de delinear, prescindindo da teleologia, a gênese de sua poética sertaneja.

\section{ABSTRACT}

We will approach the relations between Deus e o Diabo na Terra do Sol, 1963 fealure movie directed by Glauber Rocha, in its relation wilh western movies tradition so far developed. To accomplish that, we will draw the gender history and delineate its evolution from the early cinema until the 1960 's Hollywood productions. We will also lake a brief look at Brazilian's cangaço, or northwestern film cycle, happened belween the 1950 s and 1960's. Glauber's aesthetic education, his creative praxis and his undeniable effort lowards the establishment and renovation of Cinema Novo are also crucial points. The crossing over of these paths will help us to understand the filmmaker interests points - breakthroughs and continuities - as well as figure out, with no use of teleology, the genesis of his country poetics.

Fabiana Camara Conçalves Pereira Mestranda em Literatura Brasileira pela PUC/RJ, graduada en Cinema/ Comunicação Social pela Universidade Federal Fluminense/UFF. 


\section{I - O gênero Western - Origem e desenvolvimento (1903 até 1964)}

$O$ conceito de gênero se refere a um tipo ou estilo de narrativa. O que distingue um gênero de outro é seu conjunto de convenções características, que vão da estilística formal aos temas, passando inclusive pela atitude ética que adota, a "moral da história" (BORDWELL, 1985). Toda tradição narrativa guarda um conjunto de gêneros mais ou menos definidos: eles são as estruturas disponiveis para as novas investidas do relato - reiterativas ou desafiantes. Através do reconhecimento de tais sistemas narrativos torna-se mais viável interpretar um sentido para o texto. Assim como o desenvolvimento do romance no século XIX propiciou o aparecimento dos diversos gêneros literários, a evolução da gramática visual, e logo depois audiovisual, do cinema no século XX forneceu os elementos necessários para o florescimento dos gêneros também neste veículo.

Apesar dos limites de qualquer gênero serem necessariamente fluidos, condição sine qua non para sua revisitação, reprodução e continuidade, é possível delinear as principais características comuns aos filmes de Western, fundamentais na topografia deste gênero, conforme nos indicam Robert Allen e Douglas Gomery (1993):

1. Ambientação geográfica nas grandes planícies desérticas do longínquo oeste ( $f a r$ west, de onde surgiu a corruptela portuguesa 'faroeste') norte-

74 americano, em descampados inóspitos onde estão localizados pequenos povoados ou vilas distantes dos centros urbanos.

2. O conflito central gira em torno do avanço de determinada civilização ou poderes instituídos contra a anarquia e/ou o primitivismo.

3. As populações destas vilas, apesar do apoio constante de forças militares governamentais, estão amiúde indefesas frente aos fora-da-lei.

4. O herói do Western é um homem solitário, honrado, que protege os locais da injustiça e da desordem e mata somente quando é preciso.

5. As mulheres são irrelevantes como personagens que fazem avançar a trama. Seu papel é passivo, reativo, estereotipado entre a inocência maternal e a devassidão dos bordéis, ou saloons - são objetos e pivôs.

É possivel reconhecer nas principais características do Western os elementos estruturais de toda a narrativa clássica do cinema norte-americano. Isto porque o Western foi um dos primeiros gêneros cinematográficos de que se tem notícia, desenvolvendo e sedimentando a linguagem dos demais. 
Inaugurou-o um filme dirigido em 1903 por Edwin S. Porter, Assalto ao Trem Pagador (The Great Train Robbery). Os atores que interpretavam os cowboys, como Tom Mix, Hoot Gibson e Buck Jones, foram os pioneiros do star system, e suas bem sucedidas carreiras, modelos de administração que ajudaram a estabelecer os pilares miticos e comerciais da indústria de cinema de Hollywood. O gênero encontrou uma entusiasmada recepção por cerca de 60 anos.

Do início do século aos anos 40 havia o Western clássico, cuja diversidade apoiava-se nos elementos acessórios da trama, uma vez que a estrutura formal ainda era muito rígida. Acompanhava esta rigidez a moral maniqueísta que norteava o sentido da narrativa, direcionada claramente ao conservador público interno nos EUA, disposto a consumir imagens e histórias edificantes de sua nova imagem nacional. Tais peliculas eram exportadas desde então, atingindo também um significativo público externo. O cinema era um lucrativo negócio de entretenimento de massas já na década de 20. Um dos pontos culminantes do Western neste periodo pode ser encontrado no aclamado filme de Jonh Ford No Tempo das Diligências (Stagecoach), de 1939.

Nos anos 50 houve uma sensivel modificação no gênero. As histórias evoluiram de simples fábulas morais, onde o bem (a familia e a ordem branca) sempre vencia o mal (o saloon, os indios e os foras-da-lei), e os filmes passavam a conter tramas de grande complexidade psicológica e social. Nesta mudança foram substituidos a temática e alguns elementos. O conflito com os índios, por exemplo, deixou de ser um tema em si - abrindo caminho para questões como o racismo. É deste tempo, 1956, o instigante Rastros de Ódio (The Searchers), do mesmo Jonh Ford - uma das referências do gênero.

Já nos anos 60 houve outra virada no Western, influenciado pelos demais movimentos estético-culturais e politico-sociais presentes na década tão agitada. A Nouvelle Vague e sua promoção do pastiche e da metalinguagem leva alguns cineastas como Sérgio Leone a dirigir Westerns altamente irônicos como Por um Punhado de Dólares (A Fistfull of Dollars), 1964, pervertendo o que ainda restava da moral conservadora dos primeiros filmes de bangue-bangue. Esta tendência durou até o final da década de 70. Depois da chegada do homem à Lua, em 1969, as fronteiras caracteristicas ao Western expandiram-se para além do planeta, e os filmes de ficção científica, mais atualizados, tornaram-se os herdeiros de algumas de suas convenções.

Conforme nos indica Glauber Rocha em sua Revisão Critica do Cinema Brasileiro (2000), o sucesso de bilheteria do filme O Cangaceiro, de Lima Barreto, animou os produtores a financiar projetos semelhantes, surgindo assim, a partir de 1952, o ciclo cinematográfico do cangaço. O gênero foi denominado nordestern pelo critico Salvyano Cavalcanti de Paiva, devido às explícitas referências. Sua filmografia é extensa e percorre toda a década de 
1960, extinguindo-se progressivamente nos anos seguintes. Fernão Ramos (1990) marca o gênero, na falta de limites mais claros, nesse período de 1952 aos fins de 60, e à narrativa em sua forma clássica, não incluindo obras mais ligadas ao Cinema Novo como Meimórias do Cangaço, de Paulo Gil Soares, filmado em 1965, ou Deus e o Diabo na Terra do Sol, dirigido por Glauber Rocha em 1964

\section{II - Glauber Rocha e o cinema brasileiro dos anos 60}

Em sua obra Cinema e Humanismo (1975), o estudioso de cinema Alberto Silva testemunhou e relatou a presença polêmica de Glauber Rocha na gênese do Cinema Novo. Pois Glauber não participou do movimento apenas com seus filmes, mas em grande parte com seus artigos, críticas (condensadas em Revisão Crítica, lançado em 1963) e principalmente com sua presença Glauber falava, e muito, sempre que tinha oportunidade, e mesmo quando não tinha. Alberto nos conta: "ele pode dizer coisas geniais e idiotas (...) porém jamais ficará calado" (SILVA, 1975: p. 26). Essa multiplicidade de relatos, muitos deles registrados, tornam possível conhecer um pouco mais da gênese criativa do autor e das idéias políticas do homem, aspectos tão entrelaçados na obra de Glauber que apenas sua análise conjunta pode fornecer diretivas para a compreensão deste legado.

Em um destes relatos gravados, uma entrevista com Alfredo Guevará, presidente do Instituto Cubano del Arte e Industria Cinematográficos; gravada em Havana em novembro de 1971, Glauber defende a instrução como requisito essencial a quaisquer autores candidatos à vanguarda artística de sua época. Diz: "O conhecimento dos dados concretos da realidade, a análise dialética dos dados concretos da realidade provocam (sic) realidades políticas e realidades estéticas" (ROCHA, E., 2002: p. 32), e exemplifica, citando o exemplo do livro Tristes Trópicos, do antropólogo francês Levi-Strauss: "um romancista brasileiro, um cineasta brasileiro que faça um filme sobre os índios, ou um romance sobre os índios, desconhecendo este nível de informação da antropologia, estará fazendo uma obra de retaguarda. Um romance sobre os índios brasileiros só será uma coisa bastante importante e revolucionária se acrescentar e reunir um conhecimento superior a isso" (ROCHA, E., 2002: p. 32-33). Glauber reflete: "É absolutamente impossível, hoje, uma obra de arte sem uma investigação sociológica, antropológica, psicanalítica dos fenômenos (...). Somente as novas realidades criam as novas linguagens, não?" (ROCHA, E., 2002: p. 50), mas reconhece a grande importância da intuição neste processo artístico-científico de descoberta do mundo "Um poeta, um cientista, um criador pode antecipar-se a uma realidade que não está manifesta (...). Ele teria somente de ter um poder de intuição fantástico para conseguir..." (ROCHA, E., 2002: p. 51 ) Glauber crê necessário para o 
com a ajuda de Alex Viany) frente ao que considerava válido ou não na história do cinema nacional até o momento. Só em 1964 conseguiu finalizar Deus e o Diabo na Terra do Sol, o primeiro longa-metragem inteiramente seu, e primeira obra a abordar o tema há tanto tempo cultivado, o sertão e seus personagens. Neste filme a composição dos planos e a sintaxe do banguebangue são patentes.

Vejamos, o western privilegia as tomadas panorâmicas e gerais, retirando muito de seu sentido épico da geografia selvagem do descampado. Para Glauber a simples presença da paisagem original na tela daria a tônica certa ao universo do filme que buscasse retratar o sertão. Ele devota algumas páginas de Revisão Crifica à condenação de Lima Barreto em O Cangaceiro. Repreende, entre outras coisas, a rodagem das cenas no interior de São Paulo, que teria prejudicado duplamente a veracidade (ou antes, desmascarado a superficialidade) da obra. A princípio, a escolha privara as cenas da vegetação característica do nordeste, os xiquexiques e favelas; depois, e mais gravemente, a tentativa de despistar esta ausência, fez Lima Barreto diminuir a duração dos planos, alterando o ritmo da montagem. O simples fato de Lima Barreto ter procurado falsear o interior paulista em sertão nordestino já modificara o teor épico de sua obra, transformando-a numa mera fita de aventura. "No western, fundado por John Ford, dominou o ritmo lento, marcado, revelador da nostalgia e da paisagem inexplorada do oeste. (...) O ritmo só se agitava quando a situação exigia: lutas, tiroteios, etc" (ROCHA, G., 1985: p. 48) $\dot{E}$ exatamente este ritmo pausado que encontramos em Deus e o Diabo na Terra do Sol, no qual a lentidão de certos planos torna-se essencial à imponência da narrativa. Para Glauber, o ritmo da montagem era o especifico filmico assim como o simbolo, o específico poético.

A critica ao filme de Lima Barreto teve também unna perspectiva mais ampla. Com ela, Glauber marca sua oposição a todos os demais realizadores do ciclo do cangaço e sua abordagem limitada do tema. Pois obras superficiais como estas privilegiavam o caráter estético do cangaço, como o chapéu e a roupa do cangaceiro, as armas, as estrelas brilhantes etc, enquanto o aspecto político era abordado através do recurso fácil do maniqueismo. Diz Glauber, ainda em Revisão Critica: "Lima Barreto criou um drama de aventuras convencional psicologicamente primário (...). O cangaço, como fenômeno de rebeldia mistico-anárquica surgido do sistema latifundiário nordestino, agravado pelas secas, não era situado" (ROCHA, G., 2000: p. 37). Estas incursões do ciclo do cangaço não correspondiam, para Glauber, à importância estratégica do tema. Dizia: "O western [é] relatório dramatizado da fixação social dos desbravadores, da sua luta contra um feudalismo que se forma rapidamente - já então uma força de domínio que encontra o combate de uma consciência que surge com os pequenos lavradores se unindo para a defesa de seus bens" (ROCHA, G., 2000: p. 37-38) Os filmes de cangaço brasileiros 
não haviam, muito menos, chegado à profundidade alcançada pela literatura brasileira dedicada ao interior, mais precisamente a de José Lins do Rego. Mas apesar das críticas a alguns filmes específicos de cangaceiros, Glauber considerava produtiva a reciclagem da tradição e continuava intitulando-se um grande defensor dos nordesterns. Sua gramática sempre fora um ótimo instrumento de comunicação, precisando apenas ser bem utilizada. Longe de desprezar referências imagéticas, ele assistia a todos os filmes disponíveis, inclusive os americanos, cuja cultura, excetuando o cinema (e depois o jazz) tendia a desprezar. Para a formação de suas idéias mais estruturais a respeito do sertão e mesmo do Brasil, ele buscava a literatura nacional.

Temos uma boa anedota a esse respeito na primeira viagem que Glauber fez a Minas Gerais, aos dezoito anos, para conhecer as cidades históricas. Uma vez lá fora convidado por seu anfitrião a um debate promovido pelo clube de cinema local ${ }^{4}$. Logo rejeitou o formalismo do ambiente e das críticas de cinema e exortou a todos que lessem as obras completas de José Lins do Rego, para que se situassem nas questões realmente relevantes da discussão cinematográfica e pudessem emitir opiniões válidas a esse (e qualquer) respeito. No ano em que $O$ Cangaceiro foi amplamente exibido nos cinemas, 1953, Glauber tinha catorze anos, a mesma idade em que, de acordo com o testemunho de Teixeira Gomes, devorava a obra de Lins do Rego, entre outras. A literatura nacional teve um papel decisivo em sua percepção dos problemas do Brasil. Ele já possuía esta bagagem quando, quatro anos depois, começou a escrever a coluna de crítica cinematográfica do Diário de Notícias, um dos principais jornais baianos, tornou-se responsável pelo programa da Rádio Excelsior sobre o mesmo assunto, além de colaborador e um dos dirigentes da revista que caracterizou sua geração na Bahia, a revista Mapa. Glauber não se furtava, portanto, a emitir a opinião comparativa dos dois tipos de obra que trataram da temática sertaneja: a literária, exemplificada por Jorge Amado, Graciliano Ramos, Gilberto Freire e José Lins do Rego, considerada mais complexa e abrangente, e a cinematográfica, representada pelos filmes do ciclo do cangaço, que até então não lhe haviam legado mais que simplismo e reacionarismo.

Com a comparação crítica entre os filmes do ciclo do cangaço e os livros do ciclo da cana de açúcar, inclusive, Glauber demonstrava ter uma concepção integrada do cinema e da literatura, sistema que analisamos hoje, passados quarenta anos, na (inter) disciplina dos Estudos Culturais. Em toda a sua vida o cineasta preparou sua práxis através da leitura, estudando para fazer, jamais para armazenar. Inversamente, o exercício nunca esteve dissociado deste estudo, fonte seminal de reflexão e inspiração ${ }^{5}$. Enquanto o western era o estilo rítmico ideal para a constituição da epopéia audiovisual, que desejava, a experiência literária brasileira mostrava-se estética e ideologicamente mais adequada à percepção das questões do sertão. A representação plástica do vaqueiro de Lins do Rego, em suas próprias palavras, 
se the avultava mais sugestiva e imponente que a dos caubóis vistos nos filmes de western. Em um artigo de jornal nos delineia sua compreensão da relação entre texto e imagem: "O cineasta varia o ritmo e a imagem sobre a matéria literária, extraindo a dimensão autêntica da criação; é onde acaba o romancista, o argumentista, e começa o cineasta, o diretor: a transposição gráfica de uma imagem ou situação literária marca o limite entre literatura e cinema." (GOMES, 2000: p. 216). O cinema se aproximaria da arte poética mais uma vez no lirismo figurado, plástico, interno ao filme.

Em artigo sobre José Lins do Rego para a revista Mapa, Glauber ressaltou a sutileza e o humanismo do escritor, para quem os cangaceiros, coronéis, beatos e vaqueiros não eram intrinsecamente bons ou maus, mas tinham simplesmente seus motivos para agir ora com generosidade ora com violência. Tal perspectivismo, visível em Deus e o Diabo na Terra do Sol, passava longe dos filmes de cangaço da linha de $O$ Cangaceiro. Neste, por exemplo, Galdino era cangaceiro porque era ruim, Teodoro era cangaceiro porque matara um homem. Mesmo quando se procurava narrar com mais isenção estava-se sujeito a falhas, notou em Revisão Critica, sobre $O$ Pagador de Promessas: "No texto de Dias Gomes, um equívoco: a força do povo, a revolta do povo, a dignidade do povo resultam num gesto evasivo..." (ROCHA, G., , 2000: p. 46). O gesto era a entrada triunfal na igreja. O catolicismo como a redenção (e fechamento narrativo) fácil dos esforços revolucionários. De acordo com o estudioso David Bordwell, o fechamento de um filme, na linguagem clássico-narrativa do cinema americano, é produto de um efeito

dramático. Não precisa, necessariamente, de uma conclusão das tramas pendentes, mas sim de um reforço na intensidade emotiva. Glauber enxergava como uma questão de discurso a precariedade dos western brasileiros realizados até então, os nordesterns. Isto condicionava, inclusive, sua pobreza estética: "(...) os elementos fundamentais [da linguagem cinematográfica] nascem do tema em qualidade mais evoluida, em estado de intriga elaborada, história a ser contada sobre determinado aspecto" (ROCHA, 1985: p. 314). Em sua opinião, toda a filmografia brasileira evoluiria em qualidade temática e estética através de uma visão reflexiva da situação e interesses do pais, e de maneira geral, da América Latina.

A inclusão das questões sociais no universo do western chegou a acontecer nos filmes americanos a partir da década de 50 . Com isso, o gênero perdera sua 'pureza' inicial, admitia Glauber, em vocabulário próprio à crítica cinematográfica da época". mas por outro lado "surgiram novas perspectivas que lançaram o cinema no domínio do depoimento histórico e da pesquisa sociológica." (GOMES, 2000: p. 75). A dita pureza do gênero era baseada na figura intocada do herói, que relativizado como ser humano talvez tenha quebrado parte do poder mítico do western, mas abriu-lhe novas possibilidades estéticas e críticas. Glauber atribuía estas modificações no 
gênero e no estilo acadêmico dos grandes cineastas americanos às diversas influências externas (as principais sendo a nouvelle vague francesa e o neorealismo italiano) e à concorrência interna, vinda da TV. Com Deus e o Diabo na Terra do Sol, o cineasta pretendeu fazer uma arte de vanguarda internacional, utilizando a riqueza expressiva da literatura de seu país para tratar de maneira sugestiva e revolucionária o tema da luta pela sobrevivência no sertão, e, metaforicamente, em quaisquer ambientes colonizados. Profundamente imbuído do conceito de justiça, o cineasta utilizar-se-ia de um gênero que privilegiasse a moral, como o western - moralidade que se manteria, mesmo com o matizamento proveniente de suas recentes considerações de ordem social. A moral da história, afinal, é apenas outro nome para a lógica narrativa, que liga e dá sentido às cenas costuradas pela montagem.

\section{IV - Forma e função}

O gênero do western, sendo o primeiro genuinamente audiovisual, expressava o próprio moralismo cinematográfico, inscrito em sua forma de narração. Mas isso só o tornava ainda mais apropriado: Glauber Rocha tencionava, quase sempre, agenciar politicamente. Desde cedo ele prestou muita atenção à ideologia das obras que analisava, e quando chegou à realização das suas, deixou claras as intenções pedagógicas. A violência vanguardista de Deus e o Diabo na Terra do Sol chamaria a atenção para os

84 problemas do terceiro mundo. Com isso, esperava surpreender o crítico $\mathrm{e}$ teórico estrangeiro distanciadamente interessado no retrato desta miséria. Pois "[nossos] processos de criação artística só o interessam na medida [em] que satisfazem sua nostalgia do primitivismo" - expôs mais tarde, em 1965, no manifesto $A$ Estétyka da Fome (GOMES, 2000: p. 328). Este manifesto clareia algumas diretivas de comportamento dos personagens glauberianos, inclusive os de Deus e o Diabo na Terra do Sol. A violência, por exemplo, presente desde os roteiros iniciais, tem sua explicação na formulação: "A mais nobre manifestação cultural da fome é a violência, o comportamento exato de um faminto" (GOMES, 2000: p. 328).

Neste texto, evidentemente, Glauber não expõe apenas seus personagens, mas a si próprio. Autor e obra em semelhante condição: "nossa originalidade é nossa fome e nossa maior miséria é que esta fome, sendo sentida, não é compreendida" (GOMES, 2000: p. 329). Originalidade não lhe faltou, e com Deus e o Diabo na Terra do Sol Glauber trouxe a Palma de Ouro do Festival de Cannes para o Brasil, focalizando aqui atenções internacionais. Mas a fome de Glauber, expressa no discurso de Corisco, neste mesmo filme, era de absoluto. Depois de Deus e o Diabo ná Terra do Sol Glauber ainda filmou outro western, $O$ Dragão da Maldade Contra o Santo Guerreiro. Mas morreu com fome tanto de revolução quanto compreensão, capturado no paradoxo da política coletiva do ambiente cultural 
brasileiro colonizado e do rompante pessoal cada vez mais radical, esferas que procurara relacionar e instrumentalizar desde o começo de sua trajetória

\section{Bibliografia}

ALLEN, Robert C., GOMERY, Douglas. Film History: Theory and Practice. New York: McGraw Hill, 1993.

AVELLAR, José Carlos. Deus e o Diabo na Terra do Sol: a limha reta, o melaço de cana e o retrato do artista quando jovem. Rio de Janeiro: Editora Rocco, 1995.

BORDWELL, David. Narration in the Fiction Film. Wisconsin: University of Wisconsin Press, 1985.

BORDWELL, David, THOMPSON, Kristin. Film Art-An Introduction. New York: McGraw Hill, 1997.

GOMES, João Carlos Teixeira. Glauber Rocha, esse vulcão. Editora Nova Fronteira, 2000.

JOHNSON, Randal \& STAM, Robert. Brazilian Cinema. New York: Columbia University Press, 1994.

RAMOS, Fernão (Org). História do Cinema Brasileiro. São Paulo: Art Editora, 1990.

ROCHA, Erik (org). Rocha que Voa. Rio de Janeiro: Editora Aeroplano, 2002.

ROCHA, Glauber. O século do cinema. Rio de Janeiro: Ed. Alhambra, 1985.

ROCHA, Glauber. Revisão Crifica do Cinema Brasileiro. São Paulo: Ed. Cosac \& Naify, 2003.

ROCHA, Glauber. Roteiros de Terceyro Mundo. Rio de Janeiro: Ed. Alhambra e Embrafilmes, 1981.

SENNA, Orlando. Depoimento gravado para extras do DVD de "Deus e o Diabo na Terra do Sol", Riofilme, s/d.

SILVA, Alberto. Cinema e Humamismo. Rio de Janeiro: Editora Pallas, 197.

\section{NOTAS}

' O morro onde sc localizam os fićis ć o único ponto contrastante com a platitude do ambiente.

${ }^{2}$ Ou talvez ambos pudessem ser classificados como anti-heróis, o que nào modificaria os atributos heróicos, que operariam em negativo.

3 O tema do filme ć a homosscxualidade. Un homem muito fcio cstá apaixonado por outro, belo, e acaba expressando esta paixão de uma mancira bem direta - segurando as partes intimas destc. $\Lambda$ ação contrasta com algumas imagens sacras da Igreja de São Francisco, como a cruz, enquanto é enfatizada, ao mesmo tempo, por outras destas 
imagens, como os lúbricos querubins. Segundo Maciel, Glauber desistiu do filme pois o assistiu escutando à música de Um Americano em Paris, e achou que o ritmo das duas obras era o mesmo. O filme sumiu. Questionado sobre sua exibição, Glauber teria dito: A Cruz na Praça será o meu Limite! Referia-se ao filme de Mário Peixoto, dado por perdido e encontrado anos após a morte do diretor.

${ }^{4}$ Maciel chama a atenção para o ato de, naquela época, haver muitos Clubes de Cinema espalhados pelas cidades provincianas. Eles eram dirigidos por amantes do cinema locais, que se encarregavam de conseguir os filmes e instruir os demais interessados na arte. Ele relata mesmo ter sido sócio do Clube de Cinema de Porto Alegre, sua cidade natal.

${ }^{5}$ Isto fica claro em quando comparamos os personagens Bentinho/Aparício/Domício, criados por Lins do Rego e Manuel/Corisco/Sebastião de Deus e o Diabo na Terra do Sol. ${ }^{6}$ Em abril de 1951 o Clube de Cinema da Bahia promoveu o I Festival Internacional do filme de curta-metragem (...). Foram convidados para realizar conferências Alberto Cavalcanti, Alex Viany, Salvyano Cavalcanti de Paiva, Luís Alípio de Barros e Vinícius de Moraes. Este último, crítico cinematográfico publicado em jornais de 1941 a 1951, era influenciado pelo pensamento de Octávio de Faria e mantinha sua discussão estética nos termos de 'pureza' e fidelidade à 'verdadeira' arte do cinema, a saber, o cinema mudo. Sua presença exemplifica tal tipo de pensamento, usual na época.

\author{
Palavras-chave \\ 1.Glauber Rocha \\ 2. Western \\ 3. Influência \\ 4. Arquivo pessoal
}

